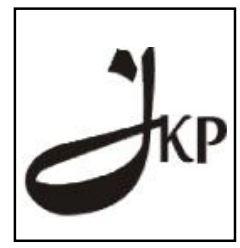

Jurnal Konseling dan Pendidikan

ISSN Cetak: 2337-6740 - ISSN Online: 2337-6880

http://jurnal.konselingindonesia.com

Volume 1 Nomor 2 Juni 2013, HIm 115-120

Info Artikel:

Diterima 05/05/2013

Direvisi 22/06/2013

Dipublikasikan 30/06/2013

Ikatan Konselor Indonesia (IKI)

\title{
Self Efficacy Mahasiswa Bimbingan dan Konseling
}

\author{
Khairul Bariyyah*
}

* Fakultas Ilmu Pendidikan, Program Studi Bimbingan dan Konseling, Universitas Kanjuruhan Malang

\begin{abstract}
Abstratc
Self-efficacy is a strong factor in determining a person to act, think and react when faced with situations that are not fun. Students with high self-efficacy tend to have persistent effort, diligent, tenacious and persevering. This research use descriptive- quantitative methodology to indentify level of self efficacy of counseling students specifically will be identified by gender, and ethnicity. This research will identify self efficacy based on differences of gender, and ethnicity. This research use random and purposive random sampling of 45 counseling students from University. These studies identify of self efficacy 31, $1 \%$ in low, 66, 7\% medium and 2,2 in high condition. Further, there is no significant difference in the level of self efficacy based on gender, and the ethnicity.
\end{abstract}

Keyword: Self-efficacy, ethnicity, counseling students

Copyright (C) 2013 IICE - Multikarya Kons (Padang - Indonesia) dan IKI - Ikatan Konselor Indonesia - All Rights Reserved Indonesian Institute for Counseling and Education (IICE) Multikarya Kons

\section{PENDAHULUAN}

Eksistensi dan kemajuan suatu bangsa sangat ditentukan oleh karakter sumber daya manusia yang dimilikinya. Hanya bangsa yang memiliki karakter kuat yang mampu menjadikan dirinya sebagai bangsa yang bermartabat dan disegani oleh bangsa-bangsa lain. Dalam usaha mencapai pembentukan karakter bangsa yang kuat juga sangat bergantung dengan taraf pendidikan di suatu bangsa tersebut. Jika bangsa berhasil membangun dasar-dasar pendidikan nasional dengan baik, maka diharapkan dapat memberikan kontribusi terhadap kemajuan dibidang-bidang lain.

Tujuan pendidikan di Indonesia menurut UU No 2 Tahun 1989 adalah menjadikan manusia Indonesia yang beriman dan bertakwa kepada Tuhan Yang Maha Esa dan berbudi pekerti luhur, memiliki pengetahuan dan keterampilan, kesehatan jasmani dan rohani, kepribadian yang mantap dan mandiri serta rasa tanggung jawab kemasyarakatan dan kebangsaan. Tujuan pendidikan ini diwujudkan baik dari pendidikan formal, informal maupun non formal. Mulai dari sekolah dasar hingga perguruan tinggi.

Perguruan tinggi merupakan salah satu subsistem pendidikan nasional yang keberadaannya dalam kehidupan bangsa dan negara berperan penting melalui penerapan Tri Dharma Perguruan Tinggi, yaitu

* Tel.: +6281937981282. E-mail address : khairulbariyyah@konselingkita.com 
pendidikan, penelitian, dan pengabdian kepada masyarakat. Tiga hal dalam tri darma perguruan tinggi ini saling berkaitan antara satu sama lain sehingga harus diterapkan secara bersamaan karena masing-masing memiliki tugas dan fungsi yang sama serta saling menunjang sehingga tidak bisa dipisahkan dalam pelaksanaannya. Tri Dharma perguruan tinggi merupakan tiga pilar dasar pola pikir dan menjadi kewajiban bagi mahasiswa sebagai bagian dari perguruan tinggi, Karena mahasiswa memiliki posisi penting sebagai pejuang terdepan dalam perubahan bangsa kita ke arah yang lebih baik.

Mahasiswa yang berada pada fase remaja akhir dan dewasa awal dipandang berada pada jenjang kehidupan manusia yang paling optimal. Dengan kematangan jasmani, perasaan dan akalnya, sangat wajar jika mahasiswa memiliki potensi yang besar dibandingkan dengan kelompok masyarakat lainya. Kepekaan yang tinggi terhadap lingkungan banyak dimiliki mahasiswa, dan pemikiran kritis mereka sangat didambakan masyarakat. Mereka juga motor penggerak kemajuan ketika masyarakat melakukan proses pembangunan. Tongkat estafet peralihan suatu peradaban terletak di pundak mereka. Baik buruknya nasib bangsa kelak, bergantung pada kondisi pemuda dan mahasiswa sekarang ini.

Tugas dan tanggung jawab yang harus dilakukan oleh seorang mahasiswa tidaklah mudah. Selain tekanan dari bidang akademis, harapan mendapatkan pekerjaan yang layak dan mapan secara ekonomi, mereka juga dituntut untuk mampu mengoptimalkan potensi yang dimilikinya sebagai suatu kebutuhan pribadi dan masyarakat. Sebagai agen perubahan sosial (agent of social change), tuntutan ini merupakan suatu hal yang sangat berpengaruh pada sebagian besar mahasiswa. Menurut Santrock(2002) ketakutan akan kegagalan dalam mencapai kehidupan yang sukses sering kali menjadi alasan munculnya stres dan depresi pada mahasiswa.

Stres telah menjadi topik penting dalam lingkup akademis maupun dalam masyarakat kita. Hans Selye mendefinisikan stres sebagai 'the nonspesific response of the body to any demand" yang artinya suatu respons tubuh yang nonspesifik dari berbagai tuntutan. Bila seseorang mengalami stres dia akan mengalami gangguan pada satu atau lebih organ tubuh sehingga yang bersangkutan tidak lagi dapat menjalankan fungsi pekerjaannya dengan baik (Kavanagh, 2005; Aldwin, 2007).

Hutabarat (2009) menjelaskan efek negatif dari terjadinya stres yaitu mempengaruhi keefektifan performa individu dalam melakukan sebuah tugas, mengganggu fungsi kognitif, dapat menyebabkan burnout, menyebabkan masalah, gangguan psikologis dan fisik. Keadaan ini berpotensi menurunkan prestasi siswa dalam bidang akademik.

Dalam menghadapi berbagai permasalahan diatas diperlukan kemampuan individu agar dapat beradaptasi terhadap kondisi tersebut dengan meningkatkan potensi diri ketika menghadapi situasi yang penuh tekanan. Salah satu kemampuan yang perlu dikembangkan oleh mahasiswa agar pencapaian prestasinya optimal adalah dengan mengembangkan keyakinan dirinya (self-efficacy). Self-efficacy dapat menumbuhkan keyakinan atas kemampuan dalam diri dan membantu mahasiswa dalam proses menuju kemandirian. Kemampuan untuk meyakini diri yang tinggi akan membuat mahasiswa menjadi lebih percaya diri dengan kemampuan yang dimiliki. Self-efficacy meliputi kepercayaan diri, kemampuan menyesuaikan diri, kapasitas kognitif, kecerdasan dan kapasitas bertindak pada situasi yang penuh tekanan.

Axford (2007) menyatakan bahwa semakin tinggi self-efficacy pada individu, maka semakin mampu individu tersebut untuk beradaptasi terhadap tantangan dan tekanan hidup. Lebih lanjut Roberts (2007) yang melakukan penelitian pada pemuda (19-22 tahun) pada komunitas militer yang berjumlah 700 orang sebagai partisipannya menemukan bahwa self-efficacy sangat berkontribusi pada resiliensi para pemuda yang menjadi partisipannya.

Self efficacy merupakan hal yang kuat dalam menentukan seseorang bertindak, berfikir dan bereaksi ketika menghadapi situasi-situasi yang tidak menyenangkan (Bandura, 2002). Artinya ketika mahasiswa mengalami situasi-situasi yang tidak menyenangkan dalam dirinya seperti sulit mengerjakan tugas, maka dengan adanya self efficacy mahasiswa tersebut mampu bertingkahlaku dan bereaksi positif untuk mengatasi situasisituasi tersebut.

Mahasiswa yang memiliki self efficacy yang tinggi cenderung memiliki usaha yang gigih, rajin, ulet dan tekun. Mereka memiliki target untuk mendapatkan nilai yang tinggi, mempunyai rasa ingin tahu lebih besar terhadap pelajaran, aktif bertanya di kelas, suka membaca dan mereview literatur, ketika menghadapi tugas-tugas yang sulit tidak mudah putus asa, dan menganggap kegagalan sebagai motivasi untuk lebih baik. Sedangkan, mahasiswa yang mempunyai self efficacy rendah cenderung merasa pemalu, dan ragu-ragu terhadap kemampuan 
yang dimilikinya, menganggap persoalan yang rumit sebagai suatu ancaman, berdiam diri, dan tidak berusaha dengan sungguh-sungguh dan menyerah begitu saja ketika berhadapan dengan kesulitan, mudah terkena stres dan depresi (Bandura, 2002).

Mahasiswa Bimbingan dan konseling sebagai calon konselor dituntut memiliki kompetensi dan kepribadian yang mendukung dalam memberikan pelayanan kepada siswanya. Sebagai calon konselor, disamping melaksanakan tugas-tugas kuliah di kampus, mahasiswa bimbingan dan konseling juga dituntut untuk dapat (1) memahami secara mendalam konseli yang dilayani, (2) menguasai landasan dan kerangka teoretik bimbingan dan konseling, (3) dapat menyelenggarakan pelayanan bimbingan dan konseling yang memandirikan, dan (4) mengembangkan pribadi dan profesionalitas konselor secara berkelanjutan (ABKIN: 2009). Tugas-tugas yang harus dipenuhi oleh mahasiswa tersebut baik tugas yang bersifat kademik maupun non akademik ini juga menuntut mahasiswa memiliki self efficacy agar mahasiswa memiliki keyakinan akan kemampuan yang dimilikinya dan dapat menjadi pribadi konselor yang professional.

Berdasarkan paparan diatas, peneliti memandang penting untuk mengidentifikasi kondisi self efficacy mahasiswa bimbingan dan konseling dan mengungkapkan apakah terdapat perbedaan tingkat self efficacy mahasiswa bimbingan dan konseling berdasarkan jenis kelamin, dan etnis.

\section{METODOLOGI}

Penelitian ini merupakan tinjauan awal yang berbentuk kuantitatif deskriptif dengan menggunakan sampel random bertujuan. Penelitian ini melibatkan 45 mahasiswa bimbingan dan konseling yang tersebar berdasarkan jenis kelamin, dan etnis. Instrument yang digunakan The College Academic Self-Efficacy Scale (CASES). Untuk menjawab pertanyaan penelitian tentang tingkat self efficacy mahasiswa, data diolah dengan menggunakan analisis deskriptif, dengan menentukan Mean (rata-rata) dihitung prosentase yang ada dalam ketegori tertentu. Sedangkan untuk membuktikan hipotes penelitian tentang perbedaan tingkat self efficacy mahasiswa berdasarkan jenis kelamin dan etnis, diolah dengan mengunakan rumus Uji - t.

\section{HASIL DAN PEMBAHASAN}

Berdasarkan hasil penelitian diperoleh data sebagai berikut: 31,1\% mahasiswa bimbingan dan konseling berada pada tingkat Self Efficacy rendah, 66,7\% berada pada tingkat Self Efficacy sedang, dan 2,2\% mahasiswa yang berada pada tingkat Self Efficacy tinggi. Sehingga rata-rata mahasiswa bimbingan dan konseling berada pada tingkat Self Efficacy sedang (66,7\%).

Hasil penelitian tentang tingkat Self Efficacy mahasiswa berdasarkan jenis kelamin menunjukkan 26,3\% mahasiswa berada pada tingkat Self Efficacy rendah, 73,7\% berada pada tingkat Self Efficacy sedang, dan tidak mahasiswa yang berada pada tingkat Self Efficacy tinggi. Sedangkan untuk mahasiswi menunjukkan 34,6\% berada pada tingkat Self Efficacy rendah, 61,5\% berada pada tingkat Self Efficacy sedang, dan 3,8\% mahasiswi yang berada pada tingkat Self Efficacy tinggi. Sehingga dapat disimpulkan bahwa rata-rata mahasiswa bimbingan dan konseling berada pada tingkat Self Efficacy sedang $(73,7 \%)$ dan rata-rata mahasiswi bimbingan dan konseling juga berada pada tingkat Self Efficacy sedang (61,5\%). Pengujian hipotesis menggunakan uji t dua sampel independen menunjukkan nilai t hitung adalah 0, 289 dengan signifikansi 0, 774 Oleh karena signifikansi 0, 774 > 0,05 maka diperoleh kesimpulan bahwa tidak terdapat perbedaan yang signifikan antara tingkat self efficacy mahasiswi dan mahasiswa dengan kata lain tidak ada perbedaan yang signifikan tingkat self efficacy berdasarkan jenis kelamin.

Lebih lanjut hasil penelitian tentang tingkat Self Efficacy mahasiswa berdasarkan etnis menunjukkan 25,8\% mahasiswa etnis jawa berada pada tingkat Self Efficacy rendah, 71\% berada pada tingkat Self Efficacy sedang, dan 3,2\% mahasiswa yang berada pada tingkat Self Efficacy tinggi. Sedangkan mahasiswa etnis non jawa 19,4 \% berada pada tingkat Self Efficacy rendah, 25,8\% berada pada tingkat Self Efficacy sedang, dan tidak ada mahasiswa yang berada pada tingkat Self Efficacy tinggi. Sehingga dapat disimpulkan bahwa rata-rata mahasiswa bimbingan dan konseling etnis jawa berada pada tingkat Self Efficacy sedang (71\%) dan rata-rata mahasiswa bimbingan dan konseling etnis non jawa berada pada tingkat Self Efficacy sedang (25,8\%). Pengujian hipotesis menggunakan uji t dua sampel independen menunjukkan $\mathrm{t}$ hitung adalah 1.238 dengan signifikansi 0,227. Oleh karena signifikansi $>0,05$ maka diperoleh kesimpulan bahwa tidak terdapat perbedaan yang signifikan antara 
tingkat self efficacy mahasiswa jawa dan mahasiswa non jawa dengan kata lain tidak ada perbedaan yang signifikan tingkat self efficacy berdasarkan etnis.

\section{PEMBAHASAN}

Kesuksesan seseorang tidak selalu dipengaruhi oleh kemampuan kognitif mereka. Ada individu yang memiliki intelegensi tinggi tetapi tidak memiliki kinerja yang baik. Namun disisi lain ada beberapa individu yang memiliki intelegensi rendah tetapi mempunyai kinerja yang sangat baik. Bagi individu yang memiliki prestasi akademik tinggi mereka mempunyai efikasi diri tinggi, begitu juga sebaliknya. Banyak penelitian yang telah membuktikan bahwa self-efficacy memegang peranan penting dalam keberhasilan akademik seseorang(Pajares, 2002). Bandura (2002) dalam penelitiannya juga menunjukkan bahwa efikasi diri akademik berpengaruh terhadap kesuksesan seseorang dalam belajar dan prestasinya. Semakin tinggi self efficacy seseorang, semakin giat dan tekun usaha-usahanya dalam mengahadapi permasalahannya, sedangkan self efficacy yang rendah dapat menghalangi usaha yang menyebabkan individu tersebut mudah putus asa.

Hasil penelitian ini menunjukkan rata-rata mahasiswa bimbingan dan konseling berada pada tingkat Self Efficacy sedang. Artinya mahasiswa bimbingan dan konseling berada pada kategori yang cukup baik namun perlu ditingkatkan agar dapat berada pada tingkat Self Efficacy tinggi. Menurut Bandura (2002) individu yang memiliki efikasi diri akademik yang tinggi akan memiliki sikap yang: (a) siap berpartisipasi lebih banyak dalam penyelesaian tugas belajar, (b) bekerja keras, (c) memiliki ketekunan lebih lama ketika menghadapi kesulitan dibandingkan mereka yang meragukan kemampuannya sendiri, (d) mendorong dirinya mencari berbagai macam usaha yang positif untuk meningkatkan prestasi dan kesejahteraan personal, (e) mempercepat ketertarikan pada suatu hal dan larut dalam keasyikan beraktivitas, (f) menjadikan tugas-tugas sulit sebagai tantangan dan terpacu untuk menyelesaikannya, (g) merencanakan tujuan yang menantang dan memelihara komitmen dengan kuat, (h) berusaha keras secara terus menerus melawan kemalasan, dan (i) jika mengalami kegagalan, maka dengan cepat memperbaikinya dan menata diri kembali.

Menurut Pajares (2002) Self-efficacy dibangun dari empat prinsip sumber informasi yang dimiliki oleh seseorang yaitu pengalaman yang telah dilalui ( enactive mastery experience), pengalaman orang lain (vicarious experiences), persuasi verbal ( verbal persuasion), dan keadaan fisiologis dan emosi (physiological and affective states). Pengalaman keberhasilan atau kesuksesan dalam mengerjakan sesuatu akan meningkatkan self-efficacy seseorang, sedangkan kegagalan juga akan menguranginnya, terutama ketika kegagalan ini terjadi pada saat efikasi dirinya belum terbentuk. Selain itu orang yang mendapatkan persuasi verbal bahwa mereka mempunyai kemampuan untuk melakukan sesuatu kemungkinan akan mengerahkan usaha yang lebih besar dibandingkan dengan orang yang mendapatkan perkataan yang meragukan dirinya.

Banyak faktor yang mempengaruhi tingkat Self-efficacy seseorang, salah satunya menurut Bandura (2002) adalah budaya dan gender. Budaya mempengaruhi self efficacy melalui nilai (value), kepercayaan (belief), dan self regulatory process yang berfungsi sebagai sumber penilaian self efficacy dan juga sebagai konsekuensi dari keyakinan akan self efficacy. Selain itu perbedaan gender berpengaruh terhadap self efficacy. Wanita lebih memiliki self efficacy yang tinggi dalam mengelola perannya. Namun pernyataan Bandura berbeda dengan hasil penelitian ini yang menunjukkan tidak ada perbedaan yang signifikan tingkat self efficacy mahasiswa berdasarkan etnis dan tidak ada perbedaan yang signifikan tingkat self efficacy mahasiswa berdasarkan jenis kelamin.

Perbedaan hasil penelitian ini dengan penyataan Bandura dapat dipahami karena Self-efficacy juga terbentuk melalui proses belajar yang dapat diterima individu pada tingkat pendidikan formal. Individu yang memiliki jenjang pendidikan yang lebih tinggi biasanya memiliki self-efficacy yang lebih tinggi, karena pada dasarnya mereka lebih banyak belajar dan lebih banyak menerima pendidikan formal. Hal inilah yang mempengaruhi mahasiswa dalam hasil penelitian ini. Mahasiswa telah banyak mendapatkan kesempatan untuk belajar dalam mengatasi persoalan-persoalan dalam hidupnya

Selain itu perkembangan diri anak terutama pembentukan kepribadiannya, dalam hal ini yaitu selfefficacynya juga sangat dipengaruhi oleh pola asuh yang diterapkan oleh orang tua. Dalam penelitian Baumrind (1991) ditemukan bahwa pola pengasuhan (parenting style) yang efektif untuk pengembangan kepribadian diri, ditandai dengan komunikasi dua arah antara orang tua dengan anak-anaknya. Dimana anak dapat merasa nyaman berada di dalam keluarganya karena merasa dihargai oleh anggota keluarga yang lain dalam hal ini terutama orang tua sehingga self-efficacy anak pun dapat lebih dikembangkan. Oleh karena itu pola pengasuhan demokratis 
cenderung memberi pengaruh yang lebih baik untuk pengembangan self-efficacy anak bila dibandingkan dengan pola pengasuhan permisif atau otoriter.

Teman sebaya juga memegang peranan penting dalam membantu mahasiswa mengembangkan identitas dirinya terutama self-efficacynya (Bandura :2002). Meskipun mahasiswa berasal dari berbagai etnis atau budaya, namun dalam sehari-hari mereka lebih banyak menghabiskan waktu dengan teman sebaya. Dalam menemukan identitas dirinya, remaja beranggapan bahwa bagaimana mereka dipandang oleh teman sebayanya merupakan hal yang penting dalam kehidupan mereka. Para remaja menerima umpan balik mengenai kemampuan mereka dari teman sebayanya. Mereka lebih mengenal apakah sesuatu yang mereka perbuat lebih baik, sama saja atau bahkan lebih buruk dari apa yang diperbuat oleh para remaja lainnya (Santrock, 2002). Pujian yang diberikan oleh teman sebayanya dapat meningkatkan self-efficacy remaja. Hal ini terjadi karena orang yang mendapatkan persuasi verbal bahwa mereka mempunyai kemampuan untuk melakukan sesuatu kemungkinan akan mengerahkan usaha yang lebih besar dibandingkan dengan orang yang mendapatkan perkataan yang meragukan dirinya. Adanya persuasi (bujukan) yang meningkatkan self-efficacy mengarahkan seseorang untuk berusaha lebih giat.

\section{SIMPULAN DAN SARAN}

Beberapa kesimpulan diperoleh dalam penelitian ini: (1) $31,1 \%$ mahasiswa bimbingan dan konseling berada pada tingkat Self Efficacy rendah, 66,7\% berada pada tingkat Self Efficacy sedang, dan 2,2\% mahasiswa yang berada pada tingkat Self Efficacy tinggi. Sehingga rata-rata mahasiswa bimbingan dan konseling berada pada tingkat Self Efficacy sedang (66,7\%), (2) Pengujian hipotesis menggunakan uji t dua sampel independen menunjukkan nilai t hitung adalah 0, 289 dengan signifikansi 0, 774 Oleh karena signifikansi 0, $774>0,05$ maka diperoleh kesimpulan tidak ada perbedaan yang signifikan tingkat self efficacy berdasarkan jenis kelamin, (3) Pengujian hipotesis menggunakan uji t dua sampel independen menunjukkan t hitung adalah 1.238 dengan signifikansi 0,227. Oleh karena signifikansi > 0,05 maka diperoleh kesimpulan bahwa tidak terdapat perbedaan yang signifikan antara tingkat self efficacy mahasiswa berdasarkan etnis.

Beberapa saran penelitian untuk peneliti lanjut adalah (1) agar menggunakan metode penelitian yang mampu menguji Self Efficacy lebih mendalam seperti interview dan observasi dan juga diharapkan mampu meneliti hal-hal yang lebih luas lagi terkait dengan Self Efficacy mahasiswa. (2) mengingat tingkat Self Efficacy mahasiswa berdasarkan hasil penelitian ini masih berada pada tingkat sedang maka perlu dilakukan sebuah penelitian eksperimen atau pengembangan dengan teknik tertentu guna membantu meningkatkan tingkat Self Efficacy mahasiswa.

\section{DAFTAR RUJUKAN}

ABKIN. (2007). Penataan Pendidikan Profesional Konselor dan Layanan Bimbingan dan Konseling dalam Jalur Pendidikan Formal. Jakarta : Depdiknas

Aldwin, Carolyn M. (2007). Stress, Coping, And Development: An Integrative Perspective. New York : Guilford Publications, Inc

Axford, K., M. (2007). Attachment, Affect Regulation, and Resilience in Undergraduate Students . Dissertation, Walden University, hlm. 64.

Bandura, A. (2002). Self-efficacy: In Changing Societies. Cambridge University Press

Baumrind,D. (1991). The influence of parenting style on adolescent competence and substance use. Journal of Early Adolescence, 11(1), 56-95

Hutabarat, D.B. (2009). Perbedaan Stres dan Coping Stres antara Laki-Laki dan Perempuan dalam Menghadapi Kemacetan Lau-Lintas. Psibernetika.02. 01. Juni. 68-87.

Kavanagh, Jennifer. (2005). Stress and performance : a review of the literature and its applicability to the military. Arlington: Rand Corporation.

Pajares, C.T. (2002). Self-Efficacy Beliefs in Academic Setting. Review of Educational Research. Florida: Educational Research Covinal Research Bulletin 
Roberts, K., A. (2007). Self-Efficacy, Self-Concept, and Social Competence as Resources Supporting Resilience and Psychological Well-Being in Young Adults Reared within the Military Community. Dissertation, Fielding Graduate University, hlm. 18.

Santrock, J.W. (2002). Life Span Development : Perkembangan Masa Hidup Terjemahan. Jakarta : Penerbit Erlangga 